\title{
The Influence of the Selected Turbulence Model and Grid Density Degree on the Results of Velocity Distribution Obtained with the Use of the Simulation Program SSIIM
}

\author{
Mateusz Hammerling ${ }^{1 *}$, Natalia Walczak ${ }^{1}$, Jakub Nieć ${ }^{1}$ \\ 1 University of Life Sciences in Poznan, Department of Water and Sanitary Engineering, ul. Piątkowska 92A, \\ 60-649 Poznań, Poland \\ * Corresponding author's e-mail: mhammer@up.poznan.pl
}

\begin{abstract}
This paper analyzed the water flow parameters in the local scour created after building stones sills No $3 \mathrm{~km} 480+$ 902 and $4 \mathrm{~km} 479+225$ below the Jeziorsko reservoir on the river Warta. The analysis was carried out using the result of field measurements (velocity distributions) and SSIIM (freeware) software. The study of the geometry of the local scour, were used to create a numerical model and implementing it to the SSIIM software. In the research, the impact of grid density on the obtained results was estimated. The results included the qualitative and quantitative assessment. The conducted analysis can be used to determine the movement of sediment in local scour, and can predict the development in time, and also specify the sill stability under different conditions of the water flow.
\end{abstract}

Keywords: velocity distribution, turbulence model, mathematical modelling, sill

\section{INTRODUCTION}

Water damming changes the hydraulic parameters of a water stream and intensifies the phenomena associated with the transport of bedload. Degradation of the riverbed and banks occurs when shear stresses associated with the water stream movement are greater than the strength of thr substrate material the bottom and banks are made of (Migoń 2006). Although erosional processes usually occur slowly, they can be accelerated due to the anthropogenic factors. Erosion of the highest intensity is found below the damming structures, behind the energy dissipation devices and bed protection (Bajkowski and Lasisz 2010). Plant debris are an organic material, e.g. grass straws, leaves, branches, brushwood, tumbleweeds, aquatic weeds, which accumulates on bars limiting the flow of water (Walczak et al. 2016)

The flow regulation results in the accumulation of bedload in the upstream of damming structures. The water stream that is deprived of bedload and flows from the upstream to the downstream of a structure is characterized by a high eroding ability. The extent of erosion and its variation in time depend on numerous factors of which the most important are: flow rate, impoundment height, hydraulic parameters and the type of material being eroded (Siwicki and Urbański 2007).

In order to limit the process of erosion and increase the water table topology, the riverbed is equipped with a stabilising sill. However, the process of local erosion still might occur below sill and its recognition is crucial to the safe operation of these facilities.

Four stages of scour development are distinguished: initial, intensive, stabilised and balanced. In the first phase, the bottom is lowered in the section below bed protection, while the scour hole is most intensively eroded and deepened. The second phase is identified by the occurrence of the bottom roller that is formed as a result of separating the boundary layer of unsupported bottom due to its lowering. The third phase characterises in the lengthening of a scour hole in the streamline direction and stabilisation of its initial 
and maximum depths. During the fourth phase, variable dimensions of a scour hole are stabilised (Hämmerling et al. 2007).

Computer simulations provide an effective alternative to difficult and expensive field research. The methods of computer simulation have an additional advantage due to various programmable options and flexibility in geometric definition of models; thus, the final result of the study can be obtained in a relatively short time and at a comparatively low cost (Siwicki and Urbański 2007).

This is particularly important with regard to describing complex processes, i.e. creation of scours. Mathematical models are verified through field research or laboratory testing. That was the observation made by Espa and Sybilla (2006) during their laboratory tests conducted with the aim to analyse the formation of a scour for non-cohesive soil at various valve openings. The authors presented changes in geometric parameters of a local scour over time and measured the velocity distributions downstream of the research model. Another aim of the study was to compare the results calculated using classical Schoklitsch and Shalash equations with the measured maximum depths of erosion. The studies of local scours on the models with protection completed with a sluice gate were presented by Kells et al. (2001), as well as D'Agostino and Ferro (2004). Chen et al. (2005) after laboratory tests stated that the length of scour is influenced by numerous factors such as: geometry of the dam, grain size of substrate material, the Froude number, critical flow rates for the initial movement of bedload particles. The research carried out by Bennet and Alonso (2006) indicated that the sheer velocity gradient, turbulent sheer stresses, bottom pressure gradients have the greatest influence on the soil erosion associated with creating a local scour. On the basis of research, Dargahi (2003) stated that the greatest effect on the process of creating a local scour is exerted by: relative grain size of bedload particles, relative roughness of bed protection, the value of the second conjugate depth (h2) and the size of whirls. On the basis of their studies, Lenzi et al. (2002), implied that the dimensions of a local scour depend on the roughness of bed protection edge. The authors also analysed the results of the geometric characteristics of local scours created for different initial conditions.

Jafari et al. (2011) used the SSIIM mathematical model for modelling the depth of a scour created below the bridge pile. The comparison of the obtained results with the experimental ones revealed their high compatibility. The numerical model created by Olsen (2014) was used for calculations, the results of which were published in the works by Wilson et al. (2003), Gamal et al. (2006), Hämmerling et al. (2015). Similar investigations carried out Xiong et al. (2014) Török et al. (2017) and Nordila et al. (2017). Lee et al. (2017) used OpenFOAM to predict the local scour caused by a submerged wall jet. The authors confirmed that the depth of the scour hole predicted by numerical model agreed with the laboratory experimental results well.

The paper presents the analysis of the velocity distributions obtained in the course of the analysis conducted during field measurements. Additionally, the authors developed a mathematical model that was subsequently verified by field research. Numerical simulations were carried out for different grid discretization variants and the selected model of turbulence.

\section{METHODOLOGY}

The analysed sill is situated below the Jeziorsko reservoir on the Warta river, which is the third largest river in Poland with its sources located in the Kraków-Częstochowa Upland. The Jeziorsko dam reservoir is a multitasking facility working in an annual cycle. The construction of the reservoir contributed to the occurrence of two major phenomena: accumulation of bedload in the reservoir and erosion below it. In order to halt the process of longitudinal erosion below the Jeziorsko reservoir in 2005, stabilising sills no. $3, \mathrm{~km}$ 480+902 and no. 4, km 479+225 (Figure 1) were built. The field research of cross sections carried out in 2011-2013 included the measurements of water table topology and flow velocity with constant water outflow of the Jeziorsko reservoir. Seven cross-sections were made for each sill.

The basis for numerical simulations was the data characterizing the topology of the river obtained from field measurements made in 2010 . The simulations were conducted based on a mathematical model developed by SSIIM (Simulation of Sediments movements In water Intakes with Multiblock). The program solves the NavierStokes equation for a turbulent flow (Olsen 2014): 


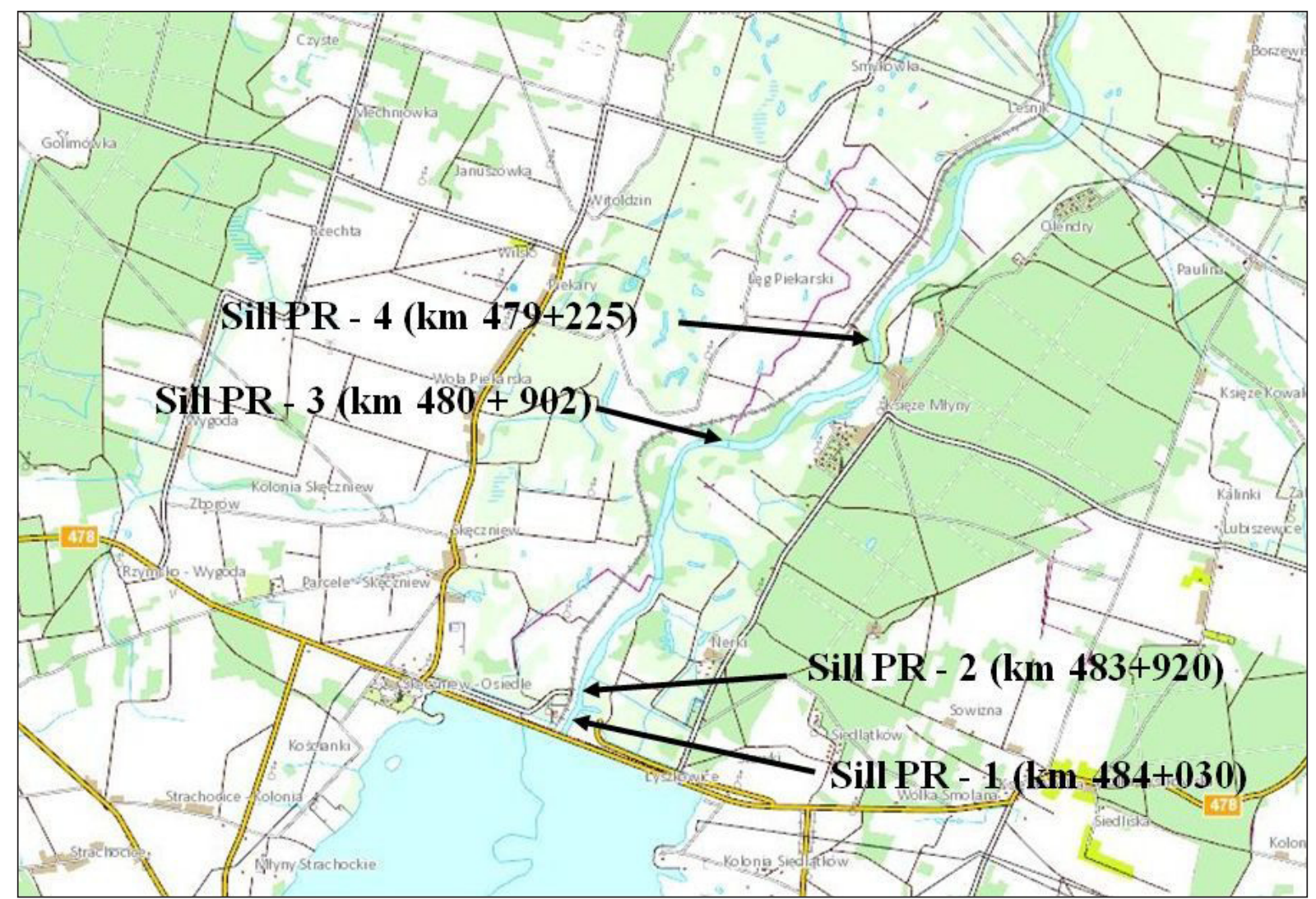

Figure 1. Location of stabilising sill below the Jeziorsko reservoir (source: geoportal.pl)

$$
\begin{gathered}
\frac{\partial u_{i}}{\partial t}+\overline{u_{j}} \frac{\partial \overline{u_{i}}}{\partial x_{j}}=\frac{1}{\rho} \frac{\partial}{\partial x_{j}} \\
\left(-p+\frac{2}{3} \rho k \delta_{i j}+v_{T} \rho \frac{\partial \overline{u_{i}}}{\partial x_{j}}+\frac{\partial \overline{u_{j}}}{\partial x_{i}}\right)
\end{gathered}
$$

where: $\delta i j-$ Kronecker delta [-]

$k$ - kinetic energy of turbulence $\left[\mathrm{m}^{2} / \mathrm{s}^{2}\right]$ $v_{T}-$ coefficient of turbulent viscosity $\left[\mathrm{m}^{2} / \mathrm{s}\right]$

The above-mentioned equation is resolved by the simulation program for a three-dimensional structural grid with the use of the finite volume method. The first stage of developing a simulation model is to prepare a grid based on the geometric data obtained during specific field research. In order to study the influence of discretization on the results, three variants of the grid that differed in density were prepared. The simulations were carried out for the flow rate of $54.0 \mathrm{~m}^{3} / \mathrm{s}$.

Solving the flow rate equations in a three-dimensional system requires the use of a turbulence model. One of the most popular and frequently used turbulence models is a standard two-equation $\mathrm{k}-\varepsilon$ model. The symbol $\mathrm{k}$ stands for kinetic energy, whereas $\varepsilon$ for kinetic energy dissipation. The concept of this model uses two additional transport differential equations to close the Reynolds equations, wherein the already known $\mathrm{k}$ equation is supplemented with the equation of the dissipation rate of turbulence kinetic energy (Bogusławski et al., 2008). The model maps turbulence in free flow and in boundary layers quite finely; however, it does not react so well to the conditions describing turbulence in the inlet area.

The turbulent flow model by Spalart-Allmaras enables to solve equations for low values of the Reynolds number and for near-critical parameters of the flow. It is an ideal solution for velocity calculations in boundary layers, including the surfaces with a very intricate geometry, at the adjacent of the place where might occur errors in the structure of the grid (Kania, 2011).

Another model that found its use to close the Reynolds equations is k- $\omega$ by Wilcox. Although it correctly reflects the turbulent flow in free flow and in the boundary layer, it is more sensitive to turbulent stress values in free flow.

Due to the shortcomings of both models, the $k-\omega$ SST model that combines the advantages of $\mathrm{k}-\varepsilon$ and $\mathrm{k}-\omega$ models was developed. In addition, the authors introduced an element limiting the in- 
a)

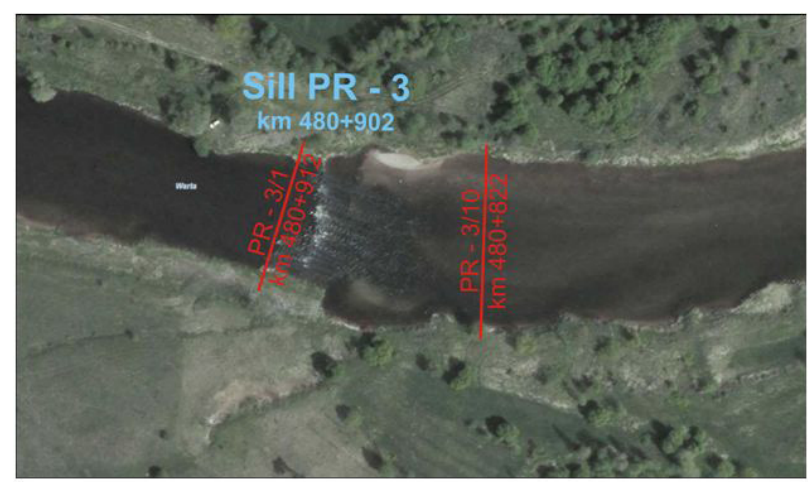

b)

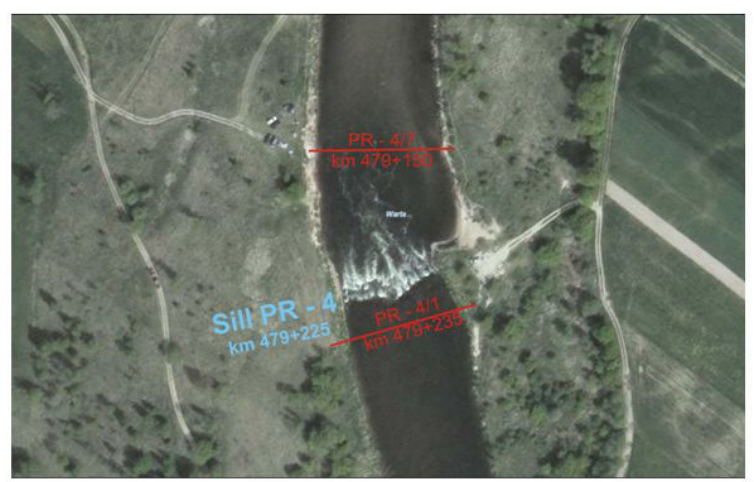

Figure 2. Location of cross sections used in the analysis of velocity distributions a) PR $-3(\mathrm{~km} 480+902)$, b) $\mathrm{PR}-4(\mathrm{~km} 479+225)$ (source: geoportal.pl)

creased values of turbulence kinetic energy in the area of strong positive pressure gradients. The k- $\omega$ SST turbulence model was used for calculation.

Discretization might be crucial for the process of developing a numerical model. The larger the grid density, the greater the accuracy of geometry mapping. This contributes to more accurate calculation results. The article presents the analysis of the grid with three different densities.

Figure 3a) presents grid I that is a basic structural grid with density including the distances between individual cross sections in accordance with the distances measured in the field. Figure $3 b)$ shows the plan for cross-sections at and below the sill no. 3 with a higher degree of density. For grid II, the distances between individual cross-sections along the riverbed were $1 \mathrm{~m}$.

a)

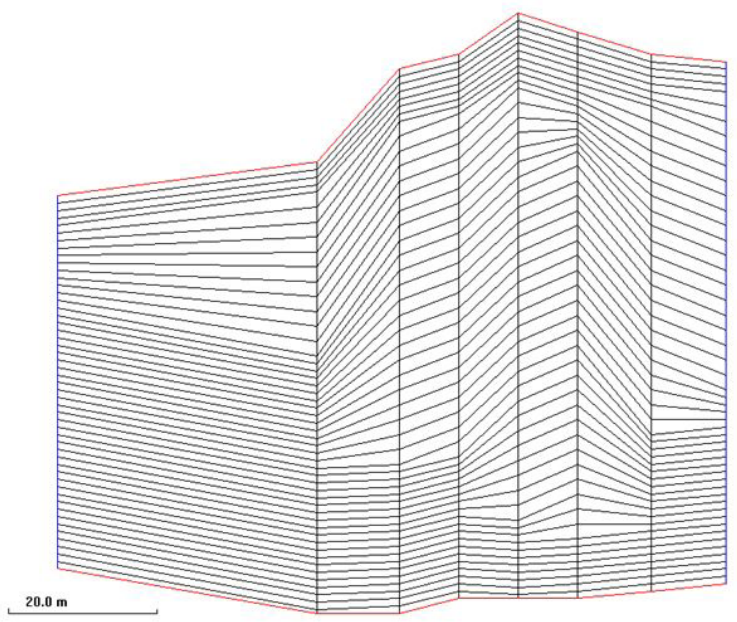

Figure 4 illustrates the third discretization variant for cross-sections at and below the sill no. 3. For grid III, the distances between individual cross-sections along the riverbed were $0.2 \mathrm{~m}$.

\section{RESULTS AND ANALYSIS}

Figure 4 shows the calculation results of the velocity distributions for the three above-mentioned numerical grid density variants in selected hydrometric verticals for each analysed sill.

On the basis of Figures 5a) and 5b) it can be estimated to what extent do the grid densities influence the obtained velocity results. The analysis led to a conclusion that despite an increased grid density, the calculation results did not change, par-

b)

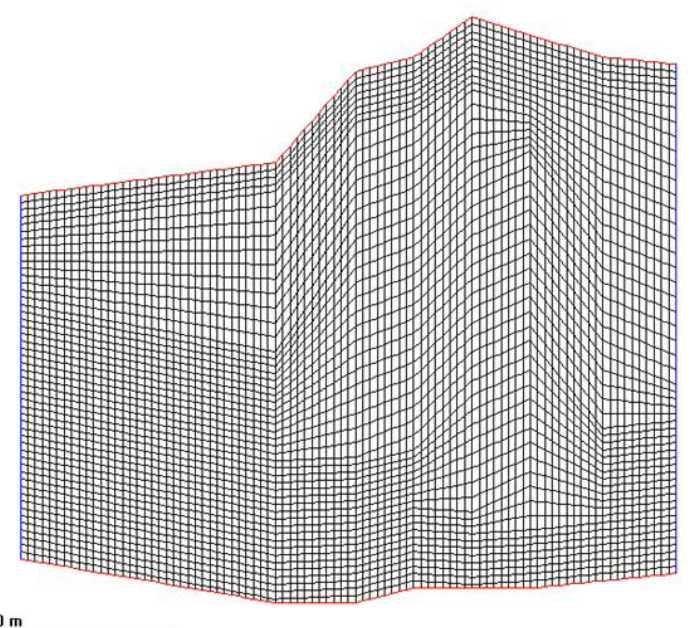

Figure 3. a) Grid I - basic structural grid for cross sections below the sill no. 3 b) grid II - dense grid for crosssections below the sill no. 3 


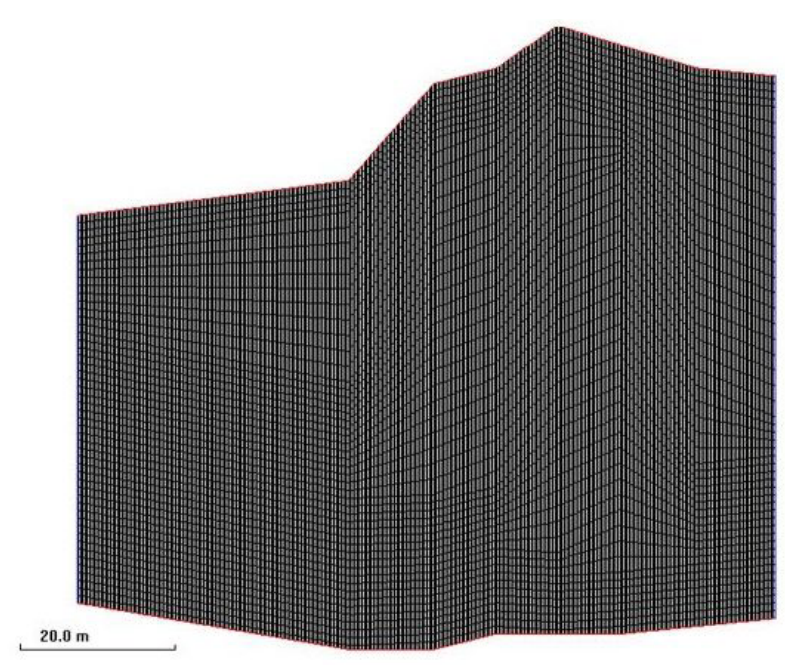

Figure 4. Grid III - dense grid for cross-sections below sill no. 3

ticularly for the hydrometric vertical no. 1 in PR $3 / 1$ cross section. A similar dependency occurred in other hydrometric verticals of this cross section. However, it was observed that an increased grid density influenced the results obtained for the hydrometric vertical no. 9 in PR 3/10 cross section. With regard to this hydrometric vertical, the best results were noticed for the grid with the third degree of discretization (the most dense).

The velocity values in hydrometric verticals measured and calculated for the sill no. 4 were subject to the same assessment (Fig. 6). The velocity results obtained taking into account various degrees of grid density did not differ from each other. The results obtained for the lowest grid density were the closest to the velocity field measurements.

More accurate mapping of the velocity values measured in the field and obtained from modelling with the grid of varying density degrees characterised the hydrometric vertical no. 1 in PR4/7 cross section. A greater difference in values presented the hydrometric vertical no. 7 in PR4/1 cross section.

A further part of the paper describes the results of velocity simulations with the use of the turbulence model k- $\omega$ SST. The legitimacy of this choice is proved by its hybrid nature that combines the model k- $\varepsilon$ with the model $\mathrm{k}-\omega$. It also finds confirmation in numerous studies a)

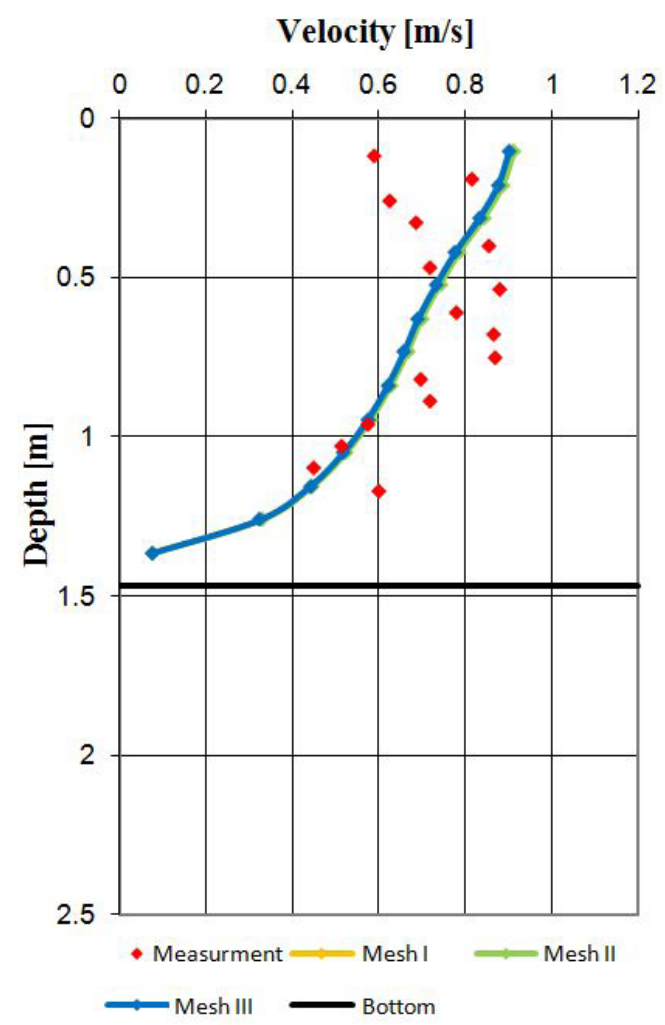

b)

\section{Velocity $[\mathrm{m} / \mathrm{s}]$}

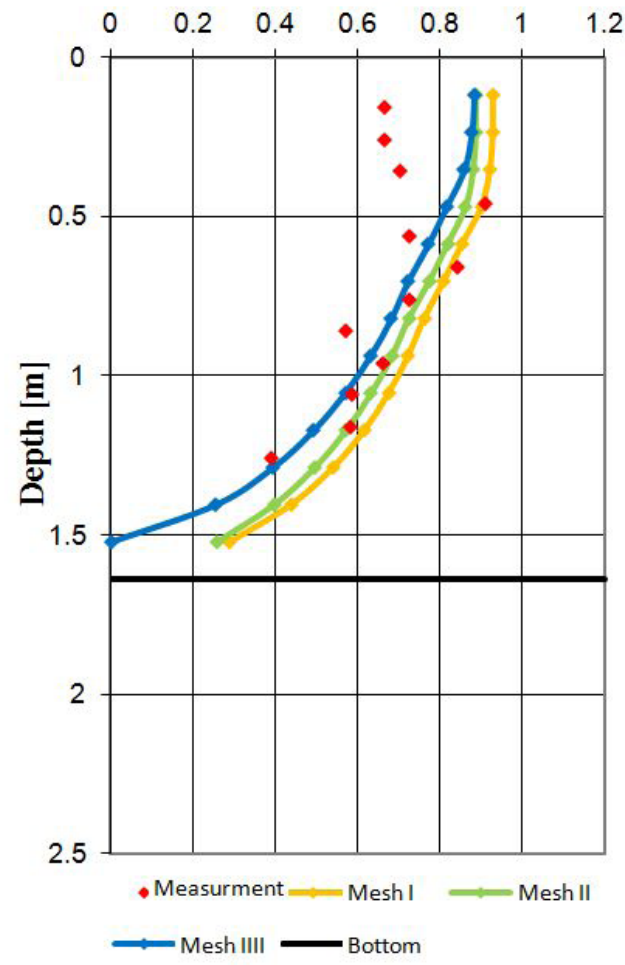

Figure 5. a) Comparison of the influence of grid discretization degree on the accuracy of calculation results for the hydrometric vertical no. 1 in PR 3/1 cross section and b) for the hydrometric vertical no. 9 in PR 3/10 cross section 
a)

\section{Velocity [m/s]}

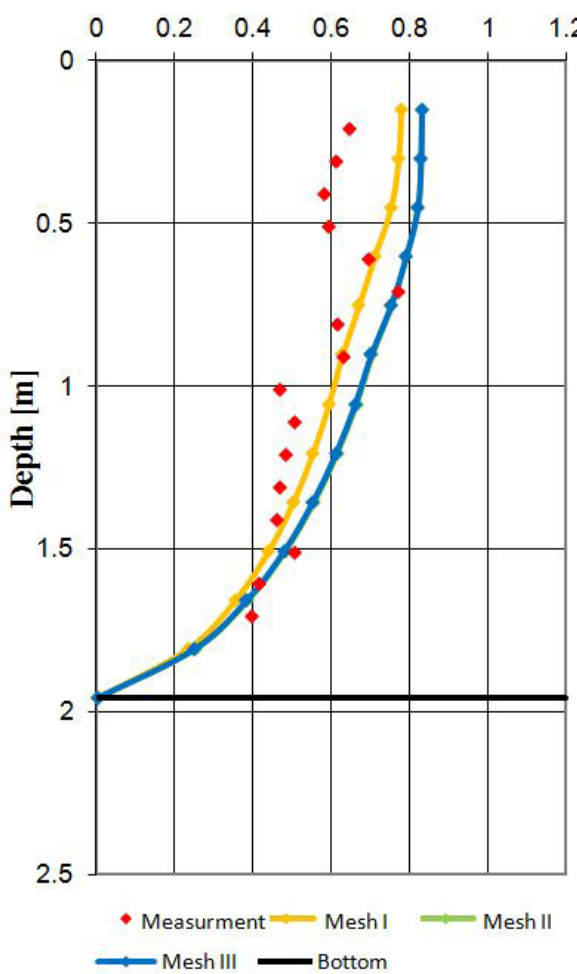

b)

\section{Velocity [m/s]}

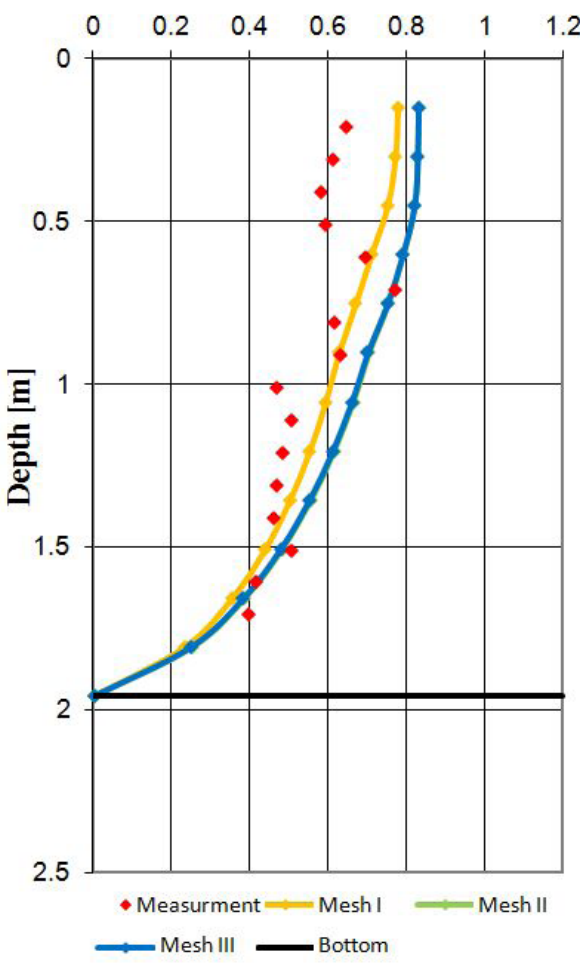

Figure 6. a) Comparison of the influence of the grid discretization degree on the accuracy of calculation results for the hydrometric vertical no. 7 in PR 4/1 cross section; b) or the hydrometric vertical no. 1 in PR 4/7 cross section.

conducted, among others, by Domański 2014, Musiał and Karcz (2015).

Table 1 summarises the results obtained from field measurements and designated from modelling with the use of the turbulence model of velocity values k- $\omega$ SST for selected hydrometric verticals of the sill no. 3 and 4 . The results are shown graphically in Figure 7.

Figure 7 a) presents the comparison of the simulation results with the use of k- $\omega$ SST model with measurement results for PR3/10 cross section, $46.67 \mathrm{~m}$ from the left bank of the river.

Table 1. Comparison of the velocity values measured and calculated using a mathematical model

\begin{tabular}{|c|c|c|c|c|c|c|c|}
\hline Cross section & $\begin{array}{c}\text { Depth, } \\
\text { m }\end{array}$ & $\begin{array}{c}\text { Turbulent model } \\
\text { k- } \omega \text { SST, } \\
\mathrm{m} / \mathrm{s}\end{array}$ & \begin{tabular}{|c} 
Field \\
measurement, \\
$\mathrm{m} / \mathrm{s}$
\end{tabular} & $\begin{array}{l}\text { Cross } \\
\text { section }\end{array}$ & $\begin{array}{l}\text { Depth, } \\
\text { m }\end{array}$ & $\begin{array}{c}\text { Turbulent model } \\
\text { k- } \omega \mathrm{SST} \\
\mathrm{m} / \mathrm{s}\end{array}$ & $\begin{array}{c}\text { Field } \\
\text { measurement, } \\
\mathrm{m} / \mathrm{s}\end{array}$ \\
\hline \multirow{12}{*}{ PR3/10 } & 0.1 & 0.85 & & \multirow{12}{*}{$\mathrm{PR} 4 / 7$} & 0.15 & 0.83 & \\
\hline & 0.2 & 0.84 & 0.68 & & 0.32 & 0.82 & 0.62 \\
\hline & 0.3 & 0.82 & 0.70 & & 0.48 & 0.81 & 0.82 \\
\hline & 0.38 & 0.78 & 0.70 & & 0.63 & 0.78 & 0.75 \\
\hline & 0.52 & 0.73 & 0.69 & & 0.80 & 0.72 & 0.72 \\
\hline & 0.59 & 0.68 & 0.65 & & 0.95 & 0.68 & 0.62 \\
\hline & 0.65 & 0.61 & 0.58 & & 1.12 & 0.65 & 0.55 \\
\hline & 0.75 & 0.62 & 0.47 & & 1.28 & 0.60 & 0.55 \\
\hline & 0.82 & 0.58 & 0.47 & & 1.45 & 0.55 & 0.48 \\
\hline & 0.95 & 0.50 & 0.43 & & 1.60 & 0.45 & 0.45 \\
\hline & 1.05 & 0.40 & & & 1.78 & 0.38 & 0.52 \\
\hline & 1.1 & 0.25 & & & 1.92 & 0.22 & \\
\hline
\end{tabular}


a)

\section{Velocity $[\mathrm{m} / \mathrm{s}]$}



b)

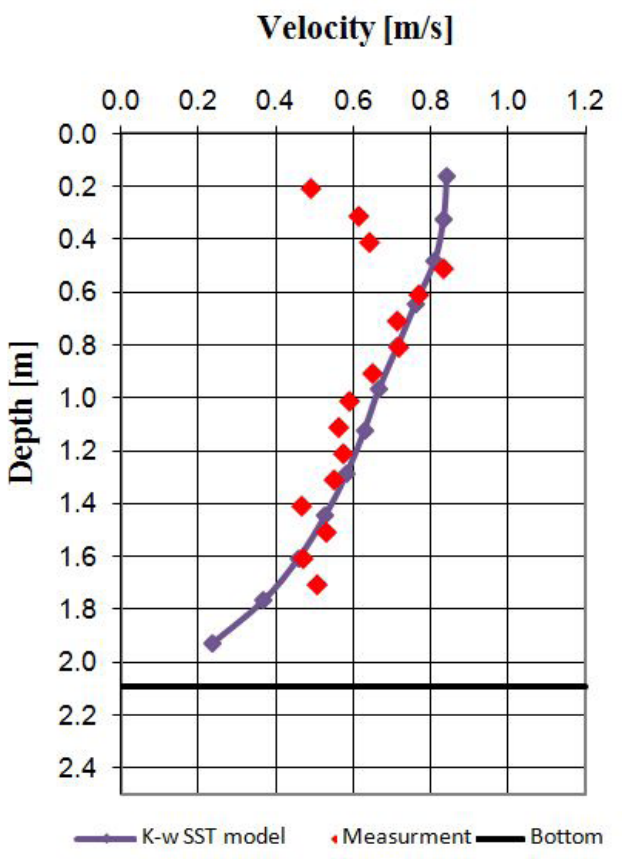

Figure 7. Vertical velocity distribution measured and simulated for the turbulence model k- $\omega$ SST for a) hydrometric vertical no. 6 in PR 3/10 cross section b) hydrometric vertical no. in PR 4/7 cross section

Figure $7 \mathrm{~b}$ ) shows the comparison of the numerical calculation results with the use of $k-\omega$ SST with measurement results for PR 4/7 cross section, $16,98 \mathrm{~m}$ from the left bank of the river. The analysis of the results implied a significant convergence of values simulated and measured in the field. The biggest differences occurred up to $0.5 \mathrm{~m}$ below the water table and in the bottom zone. Below, there is a presentation of isolines and velocity vectors describing the plane of the numerical grid no. 16.

a)
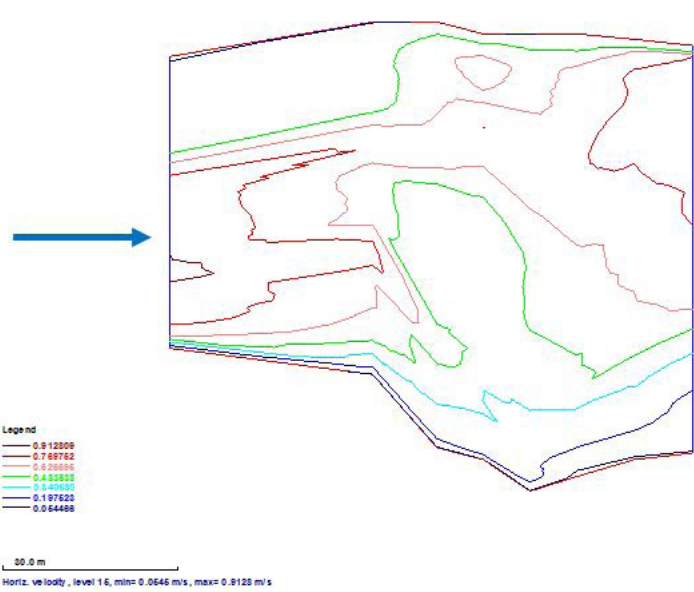

By analysing Figure 8 it can be stated that velocities assumed their maximum values (approx. $0.9 \mathrm{~m} / \mathrm{s}$ ) at the sill; however, they decreased their value in the scour due to an increase in depth. In the scour - velocities took their maximum values from the left bank of the river, which is due to the location of the sill in the meander, and were approx. $0.6 \mathrm{~m} / \mathrm{s}$. From the right bank side - velocity values were lower and took approx. $0.3 \mathrm{~m} / \mathrm{s}$. Additionally, the formation of whirls was observed below the sill at the right bank, which contributed to its erosion. b)

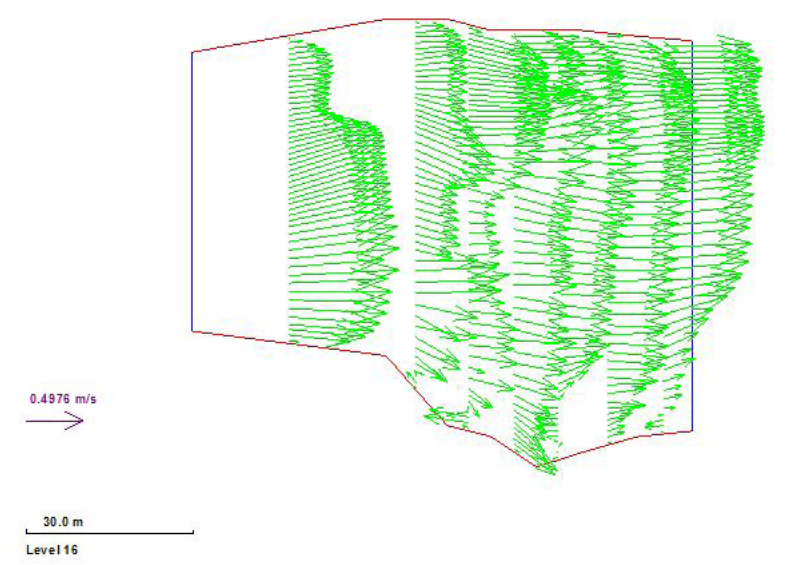

Figure 8. Velocity distributions at and below the sill no. 3 in the Warta river, km 479+225 a) isolines, b) velocity vectors 


\section{CONCLUSIONS}

The following conclusions can be drawn on the basis of the study:

1. Discretization in the process of building a numerical model has small influence on the accuracy of the obtained results.

2. SSIIM correctly describes the speed distributions below the analysed sill. The average differences between the measured and calculated velocities were approximately $12 \%$.

3 . The highest velocity was observed on the sill at the left bank and in the local scour. On the other hand, a whirlpool was present at the right bank, which can be dangerous for the construction of the threshold.

4. The rule of choosing the k- $\omega$ SST turbulence model caused from the modified formulation of the turbulent viscosity, which takes into account the effect of transport of main shear stresses.

5. Analyses of water flow velocities are very important in the context of determining the dynamics of the erosion and together with other analyses may form the basis for forecasting changes in the bottom in the local scour.

\section{REFERENCES}

1. Bajkowski S., Lasisz K. 2010. Measurements of river bed and water profile on permeable stone falls. Przegląd Naukowy Inżynieria i Kształtowanie Środowiska, 19(3) [49] (in Polish).

2. Bennett S.J., Alonso C.V. 2006. Turbulent flow and bed pressure within headcut scour holes due to plane reattached jets. Journal of Hydraulic Research, 44(4), 510-521.

3. Chen Zhicong, Shao Xuejun, Zhang Junwu 2005. Experimental study on the upstream water level rise and downstream scour length of a submerged dam, Journal of Hydraulic Research 43(6), 703-709.

4. D'Agostino V., Ferro V. 2004. Scour on alluvial bed downstream of grade-control structures. Journal of Hydraulic Engineering, 130(1), 24-37.

5. Domański M. 2014. Numerical and experimental analysis in a mixer with a stirrer an eccentric high-speed one. Doctoral thesis, ZUT, Szczecin. (in Polish).

6. Dargahi B. 2003. 'Scour development downstream of a spillway, Journal of Hydraulic Research, 41(4), 417-426.

7. Espa P., Sybilla S. 2006. Experimental study of the scour regimes downstream of apron for interme- diate tailwater depths, River Flow 2006, Taylor \& Fransis Group, London, 1715-17.

8. Gamal A.A.A., Hassan I.M., Shim M.A. 2006. 3-D numerical simulation of flow and clear water scour by interaction between bridge piers, Tenth International Water Technology Conference, IWTC10, Aleksandria, Egypt, 899-915.

9. Hämmerling M., Zawadzki P., Przedwojski B. 2007. Flow-velocity distribution below a hydraulic structure. Nauka Przyroda Technologie, 1(2), 23. (in Polish).

10. Hämmerling M., Walczak N., Szalkiewicz E. 2015. Using mathematical model SSIIM to analysis of velocity distributions: Jeziorsko reservoir on the Warta river. Acta Scientiarum Polonorum. Formatio Circumiectus, 14(2) (in Polish).

11. Jafari E., Hassunizadeh H., Zaredehdasht E., Kiuani M. 2011. Estimating Scour Depth Around Bridge Piles Using SSIIM Software and Comparing its Results with Physical Model Results, Australian Journal of Basic and Applied Sciences, 5(7), 167-173.

12. Kania M. 2011. Modelling the exhaust gases behavior from turbinę engines in rotor wake vortex in vertical helicopter flight. Modelowanie Inżynierskie, 11(42), 201-208 (in Polish).

13. Kells J.A., Balachandar R., Hagel K.P. 2001. Effect of grain size in local scour below a sluice gate, Canada Journal Civil Engineering, 28, 440-451.

14. Lenzi M.A., Marion A., Comiti F., Gaudio R., 2002. Local scouring in low and high gradient streams at bed sills, Journal of Hydraulic Research, 40(6), 731-739.

15. Lee C.H., Xu C., Huang Z. 2017. A three-phase flow simulation of local scour caused by a submerged wall jet with a water-air interface. Advances in Water Resources. (in press)

16. Migoń P. 2006. Geomorphology. Wydawnictwo Naukowe PWN (in Polish).

17. Musiał M., Karcz J. 2015. Evaluation of turbulence model impact on the numerical simulation results of two-phase gas - liquid flow in a stirred tank with the CD 6 impeller. Inżynieria i Aparatura Chemiczna (6), 342-343 (in Polish).

18. Nordila A., Thamer M., Melville B.W., Faisal A., Badronnisa Y. 2017. Modelling the Effect of Sediment Coarseness on Local Scour at Wide Bridge Piers. Pertanika Journal of Science \& Technology, 25(1), 191-200.

19. Olsen N.R.B. 2014. A three dimensional numerical model for simulation of sediments movements in water intakes with multiblock options - Users' Manual. The Norwegian University of Science and Technology.

20. Siwicki P., Urbański J. 2007. Numerical simulation of scour below the dam, Materials for XII 
Dam Monitoring International Conference, Stare Jabłonki, 19-22 June 2007. Institute of Meteorology and water management, Warsaw, 285-293.

21. Török G.T., Baranya S., Rüther N. 2017. 3D CFD Modeling of Local Scouring, Bed Armoring and Sediment Deposition. Water, 9(1), 56 (in Polish).

22. Walczak N., Walczak Z., Hämmerling M., Spychala M., Niec J. 2016. Head losses in small hydropower plant trash racks (SHP). Acta Scientiarum Polonorum-Formatio Circumiectus, 15(4), 369-382.
23. Wilson C.A.M.E., Baxall J.B., Guymer I., Olsen N.R.B. 2003. Validation of a Three-Dimensional Numerical Code in the Simulation of Pseudo-Natural Meandering Flows, Journal of Hydraulic Engineering, Vol. 129, No. 10.

24. Xiong W., Cai C.S., Kong B., Kong X. 2014. CFD simulations and analyses for bridge-scour development using a dynamic-mesh updating technique. Journal of Computing in Civil Engineering, 30(1), 04014121. 